\title{
Cross-cultural adaptation and validation of the Global Physical Activity Questionnaire among healthy Hungarian adults
}

Pongrác Ács ${ }^{1} \mathbb{D}$, József Betlehem ${ }^{1} \mathbb{D}$, András Oláh ${ }^{1} \mathbb{D}$, Barbara Bergier² ${ }^{2}$, Kata Morvay-Sey ${ }^{1} \mathbb{D}$, Alexandra Makai ${ }^{1 \dagger}$ (D) and Viktória Prémusz ${ }^{1 * \dagger}$ (D)

\begin{abstract}
Background: Physical activity (PA) is an important factor among the determinants of health due to it's protective factor and preventive role. Self-reported measures such as questionnaires are most commonly used in public health studies, but may over- or underestimate actual patterns of PA. Therefore, accelerometers are widely used to assess concurrent validity. The aim of the present study was to adapt and validate the self-administered GPAQ - Hungarian version (GPAQ-H) against accelerometer data and IPAQ-Hungarian long version (IPAQ-HL) in Hungarian healthy young adults.

Methods: A cross-sectional comparative study was conducted to examine the last 7 days PA by GPAQ-H, comparing with IPAQ-HL and Actigraph GT3X accelerometer to measure concurrent validity and reliability. A convenient sample of 300 young adults was recruited in January - July 2018 at the University of Pécs, in South-Hungary, 120 participants (age $21.53 \pm 1.75$ years, $46.66 \%$ male) were included in the validity and reliability study.

Results: Significant differences between the three instruments were found $(p<0.001)$ in all scores, except PAQs vigorous activities $(p=0.332)$ and GPAQ-H and accelerometer MVPA score $(p=0.424)$. A moderate KMO measure was found (0.538) with a significant Barlett's test of Sphericity $(279.51 ; p<0.001)$. The total variance was explained as $81.10 \%$. The reliability of the GPAQ-H instrument with all domain's scores was 0.521 ( $\mathrm{Cl} 0.371-0.644)$. We found in all intensity scores and sitting time good reliability scores $(R=0.899-987, p<0.001)$ between the baseline and follow-up ( $N=33$ random subsample). The Bland-Altman plots were showed that GPAQ-H overestimates vigorous activities by 212.75 min/week (331.82-757.42) and MVPA by 104.93 min/week (- 1016.98-807.11). A high difference, 6336.79 min/week (Cl 3638.18-9035.40) was revealed regarding sitting, as GPAQ-H largely underestimated the time spent sedentary.

Conclusions: The Hungarian GPAQ self-administered form showed fair to moderate validity with correlation coefficients similar to other European studies. Based on our study's results it could be claimed that the GPAQ-H measurement tool is a valid and reliable questionnaire to measure the healthy Hungarian population's physical activity patterns. However, our results also proved that GPAQ-H alone is not a valid and reliable questionnaire to measure sitting time.
\end{abstract}

Keywords: GPAQ, physical activity, questionnaire, accelerometer, reliability, validity, cultural adaptation

\footnotetext{
*Correspondence: premusz.viktoria@pte.hu

${ }^{+}$Alexandra Makai and Viktória Prémusz contributed equally to this work.

${ }^{1}$ Faculty of Health Sciences, University of Pécs, Pécs, Hungary

Full list of author information is available at the end of the article
}

(C) The Author(s). 2020 Open Access This article is licensed under a Creative Commons Attribution 4.0 International License, which permits use, sharing, adaptation, distribution and reproduction in any medium or format, as long as you give appropriate credit to the original author(s) and the source, provide a link to the Creative Commons licence, and indicate if changes were made. The images or other third party material in this article are included in the article's Creative Commons. licence, unless indicated otherwise in a credit line to the material. If material is not included in the article's Creative Commons licence and your intended use is not permitted by statutory regulation or exceeds the permitted use, you will need to obtain permission directly from the copyright holder. To view a copy of this licence, visit http://creativecommons.org/licenses/by/4.0/ The Creative Commons Public Domain Dedication waiver (http://creativecommons.org/publicdomain/zero/1.0/) applies to the data made available in this article, unless otherwise stated in a credit line to the data. 


\section{Background}

Physical activity is an important factor among the determinants of health due to it's protective factor and preventive role [1]. More than half of the Hungarian population is overweight and two thirds do not do sports regularly [2, 3]. Such behaviours among developed European citizens have been associated with chronic metabolic and musculoskeletal disorders such as type two diabetes, hypertension, obesity, and coronary heart disease, as well as psychological impairments and imbalanced mental health status [4-7].

The World Health Organization (WHO) guidelines and recommendations state that to maintain health, adults younger than 65 years old should perform at least $150 \mathrm{~min}$ of moderate intensity physical activity or at least $75 \mathrm{~min}$ of vigorous intensity physical activity throughout the week [8-10]. In this case physical activity (PA) has been defined as "any bodily movement produced by skeletal muscles that results in energy expenditure". The main domains of PA are work, active transportation and leisure time activities. According to intensity, moderate (4 MET) and vigorous activities (8 MET) can be classified and walking activities should be also distinguished (multiplied by 3.3 MET) [11, 12].

The monitoring techniques are useful to examine the population's activity and determine lifestyle trends. Selfreported measures such as questionnaires are most commonly used in public health studies because of the low costs, minimal burden, easy implementation, and valuable information. However, completing a self-administered PA questionnaire could be difficult to understand for participants, may induce bias, and thereby may over- or underestimate actual patterns of PA. Therefore, accelerometers are a widely used method to assess concurrent validity of PA questionnaires [13].

At the end of the twentieth century the International Physical Activity Questionnaire (IPAQ) was developed; the long form with 31 and the short form with 9 items [14, 15]. The long form has been considered too long and the short version not sufficient to analyse the physical activity patterns of the respondents. To complete and correct these deficiencies, the Global Physical Activity Questionnaire was compiled [16].

The Global Physical Activity Questionnaire (GPAQ) was developed by the World Health Organization (WHO) in 2002 and was endorsed as STEPwise Approach to the Chronic Disease Risk Factor Surveillance (STEPS). The questionnaire was constructed with special attention to the physical activity habits of the population of developing countries [17].

The first version of the GPAQ was validated in 9 countries, mostly in Asia, Africa, and South America. Based on the experience of the GPAQ v1, the GPAQ v2 was developed after minor revisions in 2005 with 16 items reflecting work, transportation, leisure time activities, and assessment of daily sitting time. GPAQ v2 was initially validated in Europe in Portugal and in Great Britain [18].

To ensure cultural adaptation of the tool, Mathews et al. developed a modified version of GPAQ according to local cultural tradition for adult women in India [13, 19]. The comparative validation study revealed significant but weak to moderate correlation between GPAQ and accelerometer data. The European validation studies showed weak to moderate correlation for moderate to vigorous PA (MVPA) $[12,20]$.

Furthermore, based on the study of Riviere et al. the IPAQ long version questionnaire proved to be an adaptive instrument to validate the GPAQ. These two quantitative techniques are similar as they contain the same domains (except the household activities which is not part of the GPAQ) and for this reason it is a relevant measurement tool to examine the concurrent validity [21].

The aim of the present study was to adapt and validate the self-administered GPAQ - Hungarian version (GPAQ$\mathrm{H})$ against accelerometer data and IPAQ-Hungarian long version (IPAQ-HL) in Hungarian healthy young adults.

\section{Methods}

\section{Study design and sample}

A cross-sectional comparative study was conducted to examine the last 7 days PA by GPAQ-H, comparing with IPAQ-HL and ActiGraph GT3X accelerometer to measure concurrent validity and reliability. A convenient sample of 300 young adults from various faculties (Law, Medicine, Technology and Informatics and Health) of the University of Pécs in Hungary was recruited in January - July 2018. The inclusion criteria were: Hungarianliterate, absence of physical disabilities, and student status at University of Pécs. The final sample contained 120 young adults as showed on Fig. 1.

Referring to a previous study [22] which assessed the criterion validity of the GPAQ against the accelerometers, a Spearman correlation, $r_{\mathrm{s}}=0.30$ was assumed for detecting a statistically significant coefficient. To achieve a power of $80 \%$ with the level of significance at 0.05 , the required sample size was 85 . Considering the sample size calculation, the total sample size was designed for 100 participants per faculty. Due the high number of exclusions and refusals, the final sample size $(N=120)$ was eligible for considering the data in total, without grouping by faculty.

\section{Procedure and measurements}

The aim of the study was explained to each participant and written informed consent was obtained before the research began by trained researchers. Participants answered a few demographic questions and anthropometric parameters were measured by OMRON B511.

Participants were asked to wear the accelerometers for a consecutive 7 days and to complete the GPAQ-H and 


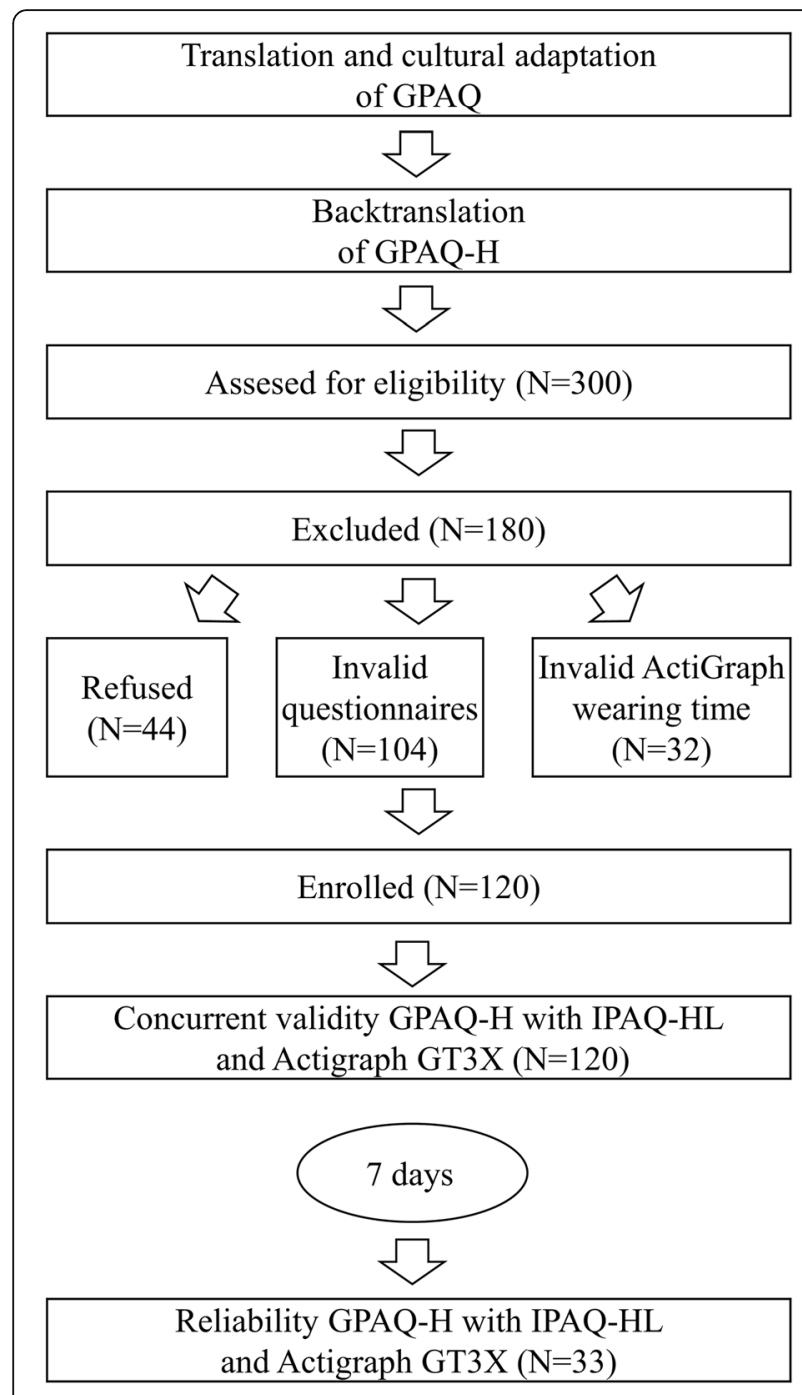

Fig. 1 Sample flow diagram for validity and reliability study of the Hungarian Global Physical Activity Questionnaire (GPAQ-H)

IPAQ-HL questionnaires in self-administered form. Seven days after the first measurement was finished, participants were asked to complete the GPAQ-H and IPAQ-HL questionnaires a second time. The latter subsample contained 33 respondents.

\section{Physical activity outcome measures \\ Global Physical Activity Questionnaire (GPAQ)}

The GPAQ version 2 was developed by the WHO, this self-administered form comprises of 16 items that measure the physical activity levels of a normal active week (7 days) of adults. The Hungarian version was developed by a scientific research group alongside native English speakers and English language experts to ensure the cultural adaptation and efficient translation of the GPAQ.

The questionnaire contains three domains of PA: work, transportation, and recreational activities. The duration and frequency of physical activity [minutes, (min/day)] were recorded in case of all three abovementioned domains.

GPAQ Analysis Guide [23] was used for scoring and data cleaning. Our study indicates data in min/week format for easier comparison with accelerometer data. Total MVPA min/week (all vigorous + all moderate activities' mins), moderate and vigorous activities in $\mathrm{min} /$ week, and weekly sitting time in min/week values were calculated [23, 24].

\section{International Physical Activity Questionnaire (IPAQ-HL)}

The Hungarian long version of IPAQ was used to test the concurrent validity of the GPAQ-H alongside the objective measurement. The questionnaire contains 27 items formed to assess the frequency, duration, and intensity of the activities of the last 7 days. The examined domains in IPAQ-HL were work, transportation, household, leisure time activities, and time spent sitting. The data were expressed in $\mathrm{min} /$ week, for calculation of the different scores the scoring protocol of the questionnaire was used [14, 25]. We summarized PA in MVPA min/ week, moderate and vigorous activities $\mathrm{min} /$ week, and sitting time in $\mathrm{min} /$ week also.

\section{ActiGraph GT3X}

Triaxial ActiGraph GT3X+ accelerometers (ActiGraph, Pensacola, FL) were used to collect data on PA with standard device initialization (sample rate of $30 \mathrm{~Hz}, 60 \mathrm{~s}$ epochs and normal filter option). Participants were asked to wear the devices for seven consecutive days during wakefulness on the right hip except for the following activities: water-based activities or contact sports. A run of zero counts lasting more than $60 \mathrm{~min}$ was defined as "non-wear time". A minimum of $480 \mathrm{~min}$ of wear-time was required daily and a minimum of 5-7 days with valid wear time (where at least 1 day was a weekend day) was required for inclusion into the analysis [26]. ActiLife 6 software was used to initialize the accelerometer and to download results.

For accurate estimation of energy expenditure (EE) accelerometer outputs were converted using the algorithm Freedson Combination for Adults (Freedson 1998), with the following cut off points: sedentary $(\leq 100$ counts min -1), light (101-1951 counts min -1), moderate (19525724 counts $\mathrm{min}-1)$ and vigorous PA ( $\geq 5725$ counts min - 1) [27]. Participants were provided with a diary to record all non-wear time (ie when the accelerometer was removed). All recording of activities with a corresponding MET value $>1.5$ were corrected for in further analysis, including activities like swimming or contact sports [28]. The average of daily moderate to vigorous physical activity (MVPA) (min / day) and sedentary behaviour (SB) (min / day) was calculated [29]. 
Validity and reliability process

COSMIN checklist and Edinburgh Framework for validity and reliability were used for the validation process.

\section{Statistical analysis}

Data were entered in Microsoft Excel and analysed using IBM SPSS 22.0 program. To present the quantitative data, mean (standard deviation, SD) and median (inter quartile range, IQR) were computed. Normality of the data was tested using Kolmogorov-Smirnov test (data was considered normally distributed if $p<0.05$ ). MannWhitney $U$ test and Chi-square test were calculated to measure the gender differences in PA levels. Factor analysis was conducted using principal component analysis (PCA) and varimax rotation. The Kaiser-Meyer-Olkin (KMO) index was calculated along with Bartlett's test and anti-image correlation.

The convergent validity between the questionnaires (GPAQ-H and IPAQ-HL) and accelerometer-based measures was determined for all of the participants and examined using Spearman's rank correlation, where $>0.40$ was considered as good, $0.30-0.40$ as moderate and $<$ 0.30 as poor validity [30]. We assessed Bland-Altman plots with 95\% limits of agreement to evaluate the extent of agreement between the accelerometer and the GPAQ-H and GPAQ-H and IPAQ-HL. To measure the internal consistency reliability, Cronbach Alpha was calculated. Intraclass correlation coefficient (ICC) was used for test retest reliability analysis of the GPAQ- $\mathrm{H}$, where above 0.75 means were interpreted as good, $0.50-0.75$ as moderate and lower means as poor reliability [11, 24]. Confidence interval of $95 \%$ was applied, and $p$ value of $<0,05$ was considered statistically significant.

\section{Results}

A total of 120 young adults were included in the validity and reliability study. Average age of the participants was $21.53 \pm 1.75$ years. The main characteristics of the sample were showed in Table 1 . The female and male participants were differed by anthropometric measures (body fat, muscle, visceral fat, waist circumference) as it was previously assumed.

Comparing the data of the three measurements, we found significant differences between the two subjective instrument in moderate $(p<0.001)$, MVPA activities $(p<$ $0.001)$, and sitting time $(p<0.001)$, but vigorous activities do not differ significantly $(p=0.332)$. GPAQ-H and accelerometer data showed significant differences in all of the marked scores: vigorous $(p<0.001)$ and moderate activities $(p<0.001)$ and sitting time $(p<0.001)$ except the MVPA scores $(p=0.424)$.

Analysis of the three instruments showed gender differences only in case of vigorous activities in GPAQ questionnaire $(p=0.046)$ and accelerometer data $(p=$ 0.048), while sitting time accelerometer data showed significant difference among female and male participants $(p=0.018)$. (Table 2).

\section{Validity and reliability of GPAQ-H Concurrent validity of the GPAQ-H instrument}

We tested the validity of the GPAQ-H by using Spearman's rank correlation between accelerometer and GPAQ-H and IPAQ-HL and GPAQ-H. (Table 3).

\section{Content validity of the GPAQ-H instrument}

The content validity of the questionnaire was examined by factor analysis using principal component analysis with varimax rotation. A moderate $\mathrm{KMO}$ measure was

Table 1 Characteristics of the sample in the adaptation and validation of the Hungarian version of the Global Physical Activity Questionnaire

\begin{tabular}{|c|c|c|c|c|c|c|c|}
\hline \multirow[t]{3}{*}{ N } & \multicolumn{2}{|l|}{ Total } & \multicolumn{2}{|l|}{ Male } & \multicolumn{2}{|c|}{ Female } & \multirow[t]{3}{*}{$p$} \\
\hline & \multicolumn{2}{|l|}{120} & \multicolumn{2}{|l|}{56} & \multicolumn{2}{|l|}{64} & \\
\hline & Mean & SD & Mean & SD & Mean & SD & \\
\hline Age (years) & 21.53 & 1.75 & 21.71 & 1.94 & 21.38 & 1.57 & 0.470 \\
\hline BMI $\left(\mathrm{kg} / \mathrm{m}^{2}\right)$ & 23.75 & 3.81 & 23.99 & 2.69 & 23.53 & 4.59 & 0.158 \\
\hline Body fat (\%) & 27.21 & 12.05 & 21.86 & 14.25 & 31.93 & 6.97 & $<0.001$ \\
\hline Muscle (\%) & 34.00 & 6.65 & 39.94 & 4.24 & 28.76 & 2.90 & $<0.001$ \\
\hline Visceral fat & 4.77 & 2.43 & 5.62 & 2.51 & 4.02 & 2.10 & $<0.001$ \\
\hline Hip circumference (cm) & 100.16 & 9.09 & 102.00 & 7.93 & 98.53 & 9.79 & 0.043 \\
\hline Waist circumference (cm) & 78.82 & 13.40 & 85.15 & 8.25 & 73.31 & 14.60 & $<0.001$ \\
\hline Place of living - urban $(\mathrm{N}, \%)$ & 96 & 80.00 & 47 & 83.93 & 49 & 76.56 & 0.314 \\
\hline Practising sport regularly ${ }^{\mathrm{a}}(\mathrm{N}, \%)$ & 63 & 52.50 & 39 & 69.64 & 24 & 37.50 & 0.071 \\
\hline Good/very good SRH (N,\%) & 81 & 67.50 & 39 & 69.64 & 42 & 65.63 & 0.393 \\
\hline
\end{tabular}

a 3 times or more in a week

SRH self-reported health status 
Table 2 Physical activity patterns of the sample based on accelerometer, self-administered IPAQ-HL, and GPAQ-H questionnaires

\begin{tabular}{|c|c|c|c|c|c|c|c|c|c|c|c|}
\hline & \multicolumn{5}{|c|}{ Male $(N=56)$} & \multicolumn{5}{|c|}{ Female $(N=64)$} & \multirow[t]{3}{*}{$\mathrm{p}$} \\
\hline & \multirow[t]{2}{*}{ Mean } & \multirow[t]{2}{*}{ SD } & \multirow[t]{2}{*}{ Median } & \multicolumn{2}{|c|}{ Percentiles } & \multirow[t]{2}{*}{ Mean } & \multirow[t]{2}{*}{ SD } & \multirow[t]{2}{*}{ Median } & \multicolumn{2}{|c|}{ Percentiles } & \\
\hline & & & & 25 & 75 & & & & 25 & 75 & \\
\hline \multicolumn{12}{|l|}{ Accelerometer } \\
\hline Moderate min/week & 332.94 & 158.11 & 332.00 & 232.71 & 438.17 & 343.51 & 115.64 & 341.42 & 255.88 & 413.50 & 0.784 \\
\hline Vigorous min/week & 9.53 & 22.61 & 0.00 & 0.00 & 0.88 & 3.91 & 13.58 & 0.00 & 0.00 & 0.00 & $0.048^{*}$ \\
\hline MVPA min/week & 342.71 & 164.06 & 343.00 & 232.71 & 438.17 & 347.98 & 114.06 & 347.75 & 265.17 & 417.83 & 0.873 \\
\hline Sitting time min/week & 9037.68 & 437.12 & 8953.58 & 8744.00 & 9302.08 & 9167.18 & 291.27 & 9187.00 & 8968.83 & 9393.63 & $0.018^{*}$ \\
\hline \multicolumn{12}{|l|}{ IPAQ-HL } \\
\hline Moderate min/week & 328.05 & 316.81 & 215.00 & 100.00 & 487.50 & 367.19 & 343.65 & 250.00 & 123.75 & 588.75 & 0.497 \\
\hline Vigorous min/week & 325.67 & 298.14 & 259.75 & 96.39 & 451.05 & 201.88 & 242.35 & 129.70 & 9.26 & 291.45 & $0.017^{*}$ \\
\hline MVPA min/week & 647.39 & 509.74 & 471.18 & 270.75 & 884.50 & 567.36 & 482.86 & 423.68 & 225.25 & 828.25 & 0.364 \\
\hline Sitting time min/week & 2618.75 & 1099.95 & 2610.00 & 2055.00 & 3435.00 & 2571.69 & 1016.49 & 2640.00 & 1815.00 & 3420.00 & 0.666 \\
\hline \multicolumn{12}{|l|}{ GPAQ-H } \\
\hline Moderate min/week & 241.07 & 299.09 & 135.00 & 22.50 & 345.00 & 222.50 & 286.11 & 120.00 & 37.50 & 333.75 & 0.779 \\
\hline Vigorous min/week & 290.07 & 349.78 & 180.00 & 60.00 & 360.00 & 157.34 & 171.83 & 120.00 & 2.50 & 262.50 & $0.046^{*}$ \\
\hline MVPA min/week & 531.14 & 539.20 & 345.00 & 143.75 & 697.50 & 379.84 & 381.55 & 285.00 & 90.00 & 551.25 & 0.150 \\
\hline Sitting time min/week & 2703.13 & 1306.28 & 2520.00 & 1680.00 & 4200.00 & 2828.44 & 1326.03 & 2940.00 & 2100.00 & 4095.00 & 0.639 \\
\hline
\end{tabular}

found (0.538) with a significant Barlett's test of Sphericity $(279.51 ; p<0.001)$. The total variance was explained as $81.10 \%$. We found five factors as follows: Factor 1 work vigorous activities, work and leisure time together (24.45\% of variance), Factor 2 moderate leisure time activities (15.99\% of variance), Factor 3 moderate work time activities (15.65\%), Factor 4 active transportation (15.10\%), and Factor 5 sitting time $(9.91 \%$ of the variance).

Internal consistency and test retest reliability of the GPAQ-H The reliability (Cronbach Alpha) of the GPAQ-H instrument with all domain's scores was 0.521 (confidence interval (CI) $0.371-0.644$ ). In our study after 7 days of the first data collection a subsample of our baseline sample completed the GPAQ-H measurement tool. We found in all intensity scores and sitting time (moderate, vigorous, MVPA and sitting time) good reliability scores $(R=0.899-987, p<0.001)$ between the baseline and follow-up scores.

Bland Altman plots demonstrated differences between the GPAQ-H and accelerometer mean values (Fig. 2). The plots showed that GPAQ-H overestimates vigorous activities by $212.75 \mathrm{~min} /$ week (331.82-757.42) and MVPA values by $104.93 \mathrm{~min} /$ week (-1016.98-807.11). A high difference, $6336.79 \mathrm{~min} /$ week (CI 3638.18-9035.40) was revealed regarding sitting, as GPAQ-H largely underestimated the time spent sedentary. Furthermore, the plots indicated wide limit of agreements for all examined parameters.

\section{Discussion}

This study showed the validity and reliability of the GPAQ-H measurement tool in comparison with accelerometer and IPAQ-HL data. Our results demonstrated fair to moderate validity of the Hungarian GPAQ compared to the accelerometer data and moderate and good correlation with IPAQ-HL questionnaire. We examined the correlation between accelerometer and questionnaires according to moderate, vigorous, MVPA activities, and sitting time values. Our results are consistent with other studies according to the intensity of the correlation coefficients.

The GPAQ-H vigorous data were showed significant moderate correlation with accelerometer-moderate and accelerometer-MVPA results, but there were no significant results with accelerometer-vigorous data. The GPAQ-H moderate values did not correlate with MVPA, only with accelerometer-moderate results. The GPAQ-H MVPA showed significant correlation with moderate and MVPA accelerometer values. The GPAQ-H sitting time did not correlate with the examined accelerometer parameters. In case of the subgroup analysis our results were similar according to genders. We noticed significant difference only by vigorous activities irrespective of the measurement method (GT3X $p=0.048$, GPAQ-H $p=0.046$, IPAQ-HL $p=0.017)$, and by objectively measured sitting time $(p=0.018)$. Otherwise, in case of the total sample, sitting time did not show a significant correlation between questionnaire and accelerometer data, but there was a significant negative correlation between accelerometer sitting time value, the GPAQ-H MVPA $(R=-0.296, p<0.001)$, and vigorous values $(R=-0.325$, 
Table 3 Concurrent validity of the GPAQ-H comparing by accelerometer and IPAQ-HL

\begin{tabular}{|c|c|c|c|c|c|c|c|c|c|c|c|c|}
\hline \multicolumn{13}{|c|}{ ActiGraph GT3X } \\
\hline & \multicolumn{4}{|l|}{ Total } & \multicolumn{4}{|c|}{ Male $(N=56)$} & \multicolumn{4}{|c|}{ Female $(N=64)$} \\
\hline & M & V & MVPA & SB & M & V & MVPA & SB & M & V & MVPA & SB \\
\hline \multicolumn{13}{|c|}{ GPAQ-H M } \\
\hline $\mathrm{R}$ & $.185^{*}$ & -.103 & .168 & -.170 & .146 & -.241 & .099 & -.053 & .224 & .049 & .239 & $-.273^{*}$ \\
\hline$p$ & .043 & .262 & .067 & .063 & .284 & .074 & .466 & .698 & .075 & .703 & .057 & .029 \\
\hline \multicolumn{13}{|c|}{ GPAQ-H V } \\
\hline $\mathrm{R}$ & $.381^{* *}$ & -.109 & $.359^{* *}$ & $-.325^{* *}$ & $.430^{* *}$ & -.099 & $.399^{* *}$ & $-.311^{*}$ & $.335^{* *}$ & -.207 & $.309^{*}$ & $-.270^{*}$ \\
\hline$p$ & $<.001$ & .235 & $<.001$ & $<.001$ & .001 & .466 & .002 & .020 & .007 & .101 & .013 & .031 \\
\hline \multicolumn{13}{|c|}{ GPAQ-H MVPA } \\
\hline $\mathrm{R}$ & $.290^{* *}$ & -.116 & $.269^{* *}$ & $-.296^{* *}$ & $.315^{*}$ & -.227 & $.264^{*}$ & -.203 & $.289^{*}$ & -.047 & $.291^{*}$ & $-.340^{* *}$ \\
\hline$p$ & .001 & .206 & .003 & .001 & .018 & .093 & .0497 & .133 & .020 & .710 & .020 & .006 \\
\hline \multicolumn{13}{|c|}{ GPAQ-H SB } \\
\hline $\mathrm{R}$ & .106 & -.014 & .098 & -.007 & .135 & .090 & .154 & -.172 & .081 & -.092 & .056 & .064 \\
\hline$p$ & .249 & .879 & .287 & .936 & .320 & .509 & .257 & .205 & .525 & .471 & .663 & .617 \\
\hline \multicolumn{13}{|c|}{ IPAQ-HL } \\
\hline & Total & & & & Male & & & & Female & & & \\
\hline & M & V & MVPA & SB & M & V & MVPA & SB & M & V & MVPA & SB \\
\hline \multicolumn{13}{|c|}{ GPAQ-H M } \\
\hline $\mathrm{R}$ & $.504^{* *}$ & $.424^{* *}$ & $.541^{* *}$ & .007 & $.526^{* *}$ & $.425^{* *}$ & $.560^{* *}$ & $-.265^{*}$ & $.484^{* *}$ & $.454^{* *}$ & $.526^{* *}$ & $.262^{*}$ \\
\hline$p$ & $<.001$ & $<.001$ & $<.001$ & .943 & $<.001$ & .001 &.$<.001$ & .048 & $<.001$ & $<.001$ & $<.001$ & .036 \\
\hline \multicolumn{13}{|c|}{ GPAQ-H V } \\
\hline $\mathrm{R}$ & $.431^{* *}$ & $.715^{* *}$ & $.623^{* *}$ & -.011 & $.422^{* *}$ & $.761^{* *}$ & $.692^{* *}$ & -.189 & $.470^{* *}$ & $.640^{* *}$ & $.564^{* *}$ & .152 \\
\hline $\mathrm{p}$ & $<.001$ & $<.001$ & $<.001$ & .908 & .001 & $<.001$ & $<.001$ & .163 & $<.001$ & $<.001$ & $<.001$ & .230 \\
\hline \multicolumn{13}{|c|}{ GPAQ-H MVPA } \\
\hline $\mathrm{R}$ & $.527^{* *}$ & $.603^{* *}$ & $.644^{* *}$ & -.013 & $.555^{* *}$ & $.653^{* *}$ & $.723^{* *}$ & $-.293^{*}$ & $.519^{* *}$ & $.546^{* *}$ & $.571^{* *}$ & $.251^{*}$ \\
\hline$p$ & $<.001$ & $<.001$ & $<.001$ & .892 & $<.001$ & $<.001$ & $<.001$ & .028 & $<.001$ & $<.001$ & $<.001$ & .046 \\
\hline \multicolumn{13}{|c|}{ GPAQ-H SB } \\
\hline $\mathrm{R}$ & -.046 & .056 & -.034 & $.378^{* *}$ & -.052 & -.098 & -.128 & $.403^{* *}$ & -.051 & .207 & .044 & $.345^{* *}$ \\
\hline$p$ & .615 & .546 & .710 & .000 & .704 & .473 & .347 & .002 & .689 & .101 & .730 & .005 \\
\hline
\end{tabular}

GPAQ-HGlobal Physical Activity Questionnaire - Hungarian Version, IPAQ-HL International Physical Activity Questionnaire - Hungarian Long Form, m/v: minute/ week, $M$ moderate, MVPA total moderate to vigorous physical activity, $S B$ sedentary behaviour, $V$ vigorous

$p<0.001)$. The GPAQ-H and IPAQ-HL questionnaires showed moderate and good correlation and similar mean values, but the overestimation of the MVPA, moderate and vigorous activities was higher in IPAQ-HL.

In the French validation study of GPAQ, Riviere et al. applied similar study design as our research group: they measured PA patterns of staff members and students $(N=92$, age $30.1 \pm 10.7,76.9 \%$ BMI $18.5-24.9)$ of the University of Lorraine, using IPAQ-LF for concurrent and ActiGraphs for criterion measures. Multiple overestimation of PA - in particular for vigorous intensity (more than tenfold) - was characteristic in case of self-reports. Regarding intensity, Riviere et al. found correlation only between vigorous activities $(R=0.38)$ and not any significant relationship between moderate activities $(R=0.10)$. Comparing total activities across all domains of GPAQ with accelerometer-moderate activity $(R=0.40)$ and with accelerometer vigorous values $(R=0.24)$, modest significance was found. They observed poor significant relationship when examining the correlation between self-reported sitting time, accelerometersitting time $(R=0.42)$, and accelerometer-moderate activities $(R=-0.22)$. By retest, the research found poor values by moderate leisure and total PA (ICC $=0.37$ and 0.58 respectively) but good or almost perfect values by total sedentary and vigorous PA at work (ICC $=0.80$ and PABAK $=0.91$ ). Comparing GPAQ and IPAQ-LF, important discrepancies were found, and the classification with level of PA was only poorly to moderately correlated by the concurrent validity (Phi coefficient 0,22-057) [21]. 


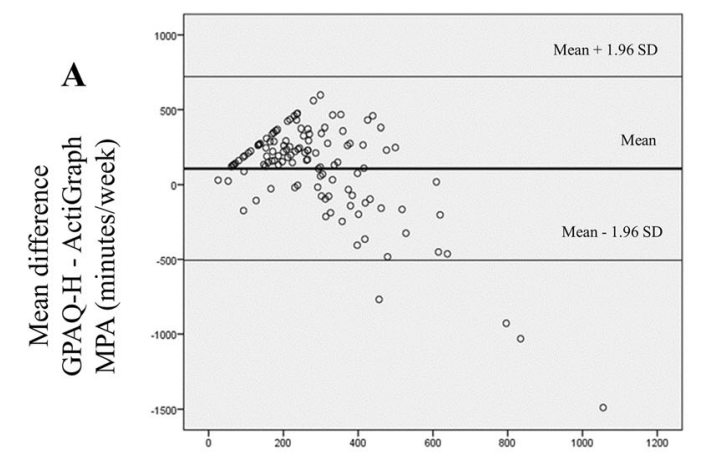

Mean GPAQ-H - ActiGraph MPA (minutes/week)

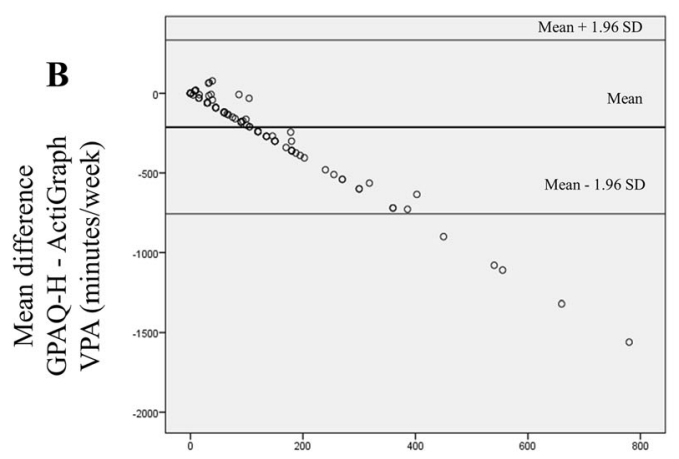

Mean GPAQ-H - ActiGraph VPA (minutes/week)

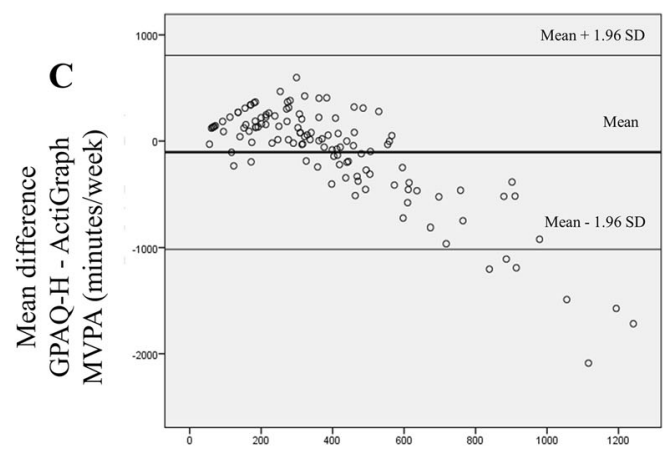

Mean GPAQ-H - ActiGraph MVPA (minutes/week)

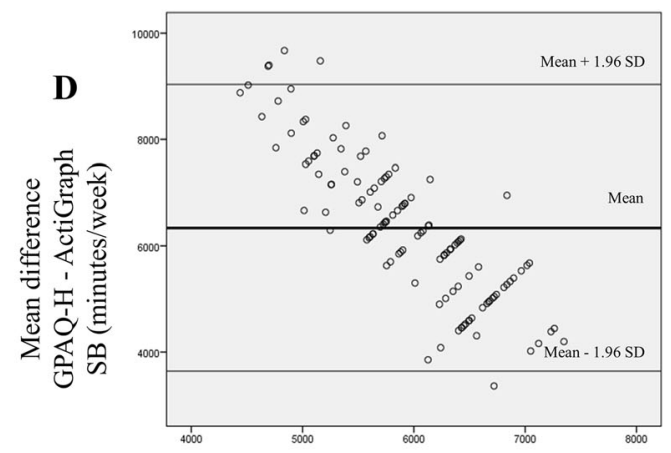

Mean GPAQ-H - ActiGraph SB (minutes/week)

Fig. 2 Bland Altman plots between GPAQ-H and accelerometer (95\% Limits of agreement)
Mumu et al. found fair to moderate correlation between objective and subjective monitoring, still claimed GPAQ as an acceptable measure, particularly among women with higher level of education despite the under-estimation of sedentary behaviour $(R=0,23, p<0.001)$ [31]. The authors explain divergence of the results by genders with PA habits, contrary of other studies [12] in favour of females. In Bangladesh - a least developed country according to United Nations classification - walking is more specific by work activities for females which is more reliably monitored with accelerometers than upper-body motions of males during intensive farming or carriage of heavy loads e.g. swimming or cycling. $60 \%$ of the sample in the study by Mumu et al. belongs to the rural population - in our study, $96 \%$ of the sample belongs to urban population. This difference may be behind more equal PA habits between genders.

Meeting PA guidelines but being highly sedentary for the rest of the days is also an emphasized risk factor [32]. Chu et al. negotiated sedentary behaviour measures, using a domain-specific Adult Sedentary Behaviour Questionnaire (ASBQ) and the Global Physical Activity Questionnaire's (GPAQ) single-item sitting question against triaxial ActiGraph wGT3X-BT accelerometers. They found significant correlation between accelerometer and GPAQ in sedentary time, while the GPAQ under-estimated the time spent sedentary. However, moderate to good test-retest reliability $(R=0.74$, ICC $0.62-0.82)$ was presented [22].

Measurement of inactivity proved to be doubtful in other studies as well. Cleland et al. found poor correlation with daily sitting time in minutes $(R=0.187)$, and reported that those people who are more sedentary were less likely to under-report their level of SB. The authors stated that this questionnaire could not be considered as a valid tool to measure sitting time [12]. They postulated both long $(R=0.33)$ and short $(R=0.34)$ form of IPAQ with higher sitting items more appropriate referring to a previous research [33]. We observed the same tendency in our study and we hypothesise that this may be due to the context of health literacy and health behaviour of participants. Describing perceived levels of activities is difficult, not only in case of SB but also regarding MVPA. Cleland et al. found only moderate correlation between the objective and subjective measurement $(R=0.484)$ of MVPA (10).

However, GPAQ was originally designed to be interviewer-administered by the WHO. Yet, similarly to many authors, we also decided to record the questionnaires in self-administrated form. The way of query did not justify bias or discrepancy in prior examinations. In the study of $\mathrm{Chu}$ et al. data with self-administration were not weaker than with interviewer-administration, yet they found only fair-to-moderate correlations for moderate-to-vigorous physical activity ( $R=0.30, R=0.46$ respectively). Strongest correlations were observed for vigorous-intensity activity (self-report $R=0.38$, with interviewer $R=0.52$ ). Bias were 
illustrated with Bland-Altman plots toward overestimation of higher levels of vigorous- and moderate-intensity activities, and underestimation for lower levels PA, parallel to similar studies in general. Reliability for MVPA revealed moderate correlations (self-report $R=0.61$, with interviewer $R=0.63$ ). To reduce bias in the GPAQ measurements they advised to incorporate accelerometers, particularly by the measurement of different intensity PA (A. H. Chu, Ng, Koh, \& Muller-Riemenschneider, 2015).

Wanner et al. measured the validity of GPAQ in European context. They found significant results as other Western countries, like fair-to-moderate validity of the GPAQ questionnaire. The range of the overestimation of the GPAQ was between 2.8-4.2 times, which mean that GPAQ results are notably higher than the accelerometer data. Total activities showed fair correlation between GPAQ and the accelerometer $(R=0.22)$, but the MVPA showed weak correlation $(R=0.11)$, while vigorous activities were moderately correlated with accelerometer $(R=$ $0.46)$ like sitting time $(R=0.47)$. The results of the Wanner et al. study showed significant difference between gender, where male participants were more likely to overestimate their vigorous activities [20]..

The reason for overestimation of time spent with MVPA may also be in relation with the lack of appropriate knowledge on adequate value of health enhancing physical activity and the perception of importance of physical activity [34]. Besides, a better understanding of the questionnaires could help to receive more accurate results. Cleland et al. also found higher validity in higher-income countries due to higher education levels [12].

Contrary to the above results, Laeremans et al. compared GPAQ results with another wearable sensor (SenseWear) in a multi-centre (Antwerp-Barcelona-London) study and demonstrated significantly lower $(p<0.05)$ time and energy expenditure (MET) in GPAQ MVPA than with SensWear. Nevertheless, the study found significant correlation $(0.45-0.64)$ between these variables. They reported also unusual findings in relation to $\mathrm{SB}$, which did not differ by various instruments, yet it was poorly correlated $(R<0.25)$. However, vigorous $P A$ values showed high similarity $(R>0.59)$ [17].

To improve the validity of GPAQ data, Metcalf et al. highlighted the utility of a Mean Squared Prediction Errors model for calibration. In this study data were collected in Ottumwa (IA, USA) and accelerometer data were predicted with a multiple regression model regarding gender, age, GPAQ PA domains by intensity and SB as covariates. The authors found weak correlation between selfreported and objectively measured data in Outcome Matching Model $\left(\mathrm{R}^{2}=0.025-0.177\right)$, but using Break Factor Cut-offs the Final Calibration Model showed considerable improvement $\left(R^{2}=0.097-0.364\right)$. In both models the proportion of variance explained of vigorous PA was the highest and SB the lowest. Mean Squared Prediction Errors reduced from $66.4-98.3 \%$ to $61.3-98.6 \%$ [19]. Majority of these studies show that, compared to other PA questionnaires, the GPAQ is more appropriate for monitoring physically active people and activities with higher energy expenditure.

While this current study focused on young adults, aging people belonging to a high risk population, should be negotiated with particular attention. Results from the GPAQ study of Hamrik et al. (carried out in the Czech Republic, a region which is socio-economically similar to Hungary) highlighted that more than $60 \%$ of the studied population across all ages could be described as sedentary, but the levels of PA decrease more with age (OR/95\% CI1.011/ $\left.1.005-1.017 ; \mathrm{F}^{\text {age }}=8.002, p<0.001\right)$. They reported the highest level of sedentary behaviour over 65 years [35]. These facts indicate the need for repeated monitoring of PA through the lifespan. While GPAQ is not suitable for reporting changes in individual PA habits, it appears to be a valid tool for monitoring national strategies for PA promotion, especially for MVPA [12].

\section{Limitations}

However, the Hungarian results confirmed that GPAQ is a valid and reliable tool to examine the Hungarian population's physical activity level, it should be borne in mind that self-administration of data can be a challenge [20], GPAQ as other subjective measurements based on self-reported data, can over or underestimates values of the physical activity level [36]. On the other hand, opposite to the self-report measures accelerometer do not register the cycling, contact sport and swimming time and it was not wearing all day.

GPAQ is a widely used tool to measure the effect of interventions at population- or community level, but it is not an efficient tool to measure changes in an individual's physical activity [12].

\section{Conclusion}

The Hungarian GPAQ self-administered form showed fair to moderate validity with correlation coefficients similar to other European studies. Based on our study's results it could be claimed that the GPAQ-H measurement tool is a valid and reliable questionnaire to measure the healthy Hungarian population's physical activity patterns. The validity is fair to moderate but acceptable, like other similar Europeans studies. Our results also proved that GPAQ-H alone is not a valid and reliable questionnaire to measure sitting time.

\section{Abbreviations}

ASBQ: Adult Sedentary Behaviour Questionnaire; BMI: Body mass index; CA: Cronbach's Alpha; ICC: Intraclass correlation coefficient; GPAQ: Global Physical Activity Questionnaire; IPAQ: International Physical Activity Questionnaire; IQR: Inter quartile range; KMO: Kaiser-Meyer-Olkin; 
MET: Metabolic equivalent of task; MVPA: Moderate to vigorous physical activity; PAQs: Physical activity questionnaires; PCA: Principal component analysis; SB: Sedentary behaviour; SD: Standard deviation; SRH: Self-reported health; WHO: World Health Organization; STEPS: STEPwise Approach to the Chronic Disease Risk Factor Surveillance

\section{Acknowledgements}

We want to thank all the students participated in our study.

\section{About this supplement}

This article has been published as part of BMC Public Health Volume 20 Supplement 1, 2020: Level and Determinants of Physical Activity in the V4 Countries - Part 1. The full contents of the supplement are available online at URL.https://bmcpublichealth.biomedcentral.com/articles/supplements/ volume-20-supplement-1

\section{Authors' contributions}

All authors read and approved the final manuscript. PÁ conceived, designed and managed the study, JB, AO and BB contributed to the study conceptualization and provided critical editorial input to the interpretation of the data, KMS contributed in collection and analysis of participants anthropometric and accelerometer data, VP and AM contributed to the data collection and analysis, and to the drafting and final editing of the manuscript.

\section{Funding}

The publication costs were funded by the Human Resource Development Operational Programme, grant No.: HRDOP-3.6.2-16-2017-00003, Cooperative Research Network in Economy of Sport, Recreation and Health. The authors declare that the design of the study and collection, analysis, and interpretation of data and writing of the manuscript are independent of the Human Resource Development Operational Programme.

\section{Availability of data and materials}

The dataset supporting the conclusions of this article is available from the corresponding author on reasonable request.

\section{Ethics approval and consent to participate}

The ethical approval was granted for the study by Ethics Committee of University of Pécs (Nr. 6955/2017). Participants were informed about the research aim and methods before signing the informed consent form. The investigation conforms to the principles outlined in the Declaration of Helsinki.

\section{Consent for publication}

Not applicable.

\section{Competing interests}

The authors declare that they have no competing interests.

\section{Author details}

${ }^{1}$ Faculty of Health Sciences, University of Pécs, Pécs, Hungary. ${ }^{2}$ Pope John Paul II. State School of Higher Education, Biała Podlaska, Poland.

Received: 3 March 2020 Accepted: 6 March 2020

Published: 17 August 2020

\section{References}

1. Piercy KL, Troiano RP, Ballard RM, Carlson SA, Fulton JE, Galuska DA, George SM, Olson RD. The Physical Activity Guidelines for Americans. JAMA. 2018; 320(19):2020-8.

2. Ács P, Prémusz V, Morvay-Sey K, Kovács A, Makai A, Elbert G. Changes of sport and physical activity indicators in Hungary and in the European Union according to the results from recent years (A sporttal, testmozgással összefüggésben lévő mutatók változása Magyarországon és az Európai Unióban az elmúlt évek eredményeinek nyomán). Sport- és egészségtudományi füzetek. 2018;2(1):61-76.

3. The Hungarian Diet and Nutritional Status Survey 2014 (Országos Táplálkozás és Tápláltsági Állapot Vizsgálat 2014) [https://www.ogyei.gov.hu/ otap_2014/] Accessed: 10 Oct 2017.

4. Watson ED, Micklesfield LK, van Poppel MNM, Norris SA, Sattler MC, Dietz P. Validity and responsiveness of the Global Physical Activity Questionnaire (GPAQ) in assessing physical activity during pregnancy. PLoS One. 2017;12(5):1-14.
5. Chu AHY, Moy FM. Reliability and Validity of the Malay International Physical Activity Questionnaire (IPAQ-M) Among a Malay Population in Malaysia. Asia Pac J Public Health. 2015;27(2):NP2381-9.

6. Bhola N, Kumari R, Bansal D. Pattern of physical activity and associated sociodemographic factors: A community based study using Global Physical Activity questionnaire. Ceylon Med J. 2018;63(4):159-68.

7. Ostojic SM, Stojanovic MD, Stojanovic V, Maric J, Njaradi N. Correlation between fitness and fatness in 6-14-year old Serbian school children. J Health Popul Nutr. 2011;29(1):53-60.

8. WHO. Global action plan on physical activity 2018-2030: more active people for a healthier world. Switzerland: World Health Organization; 2018.

9. Physical activity strategy for the WHO European Region 2016-2025 [http:// www.euro.who.int/_data/assets/pdf_file/0010/282961/65wd09e_ PhysicalActivityStrategy_150474.pdf?ua=1] Accessed: 06 Nov $201 \overline{8}$

10. Lee IM, Shiroma EJ, Lobelo F, Puska P, Blair SN, Katzmarzyk PT. Effect of physical inactivity on major non-communicable diseases worldwide: an analysis of burden of disease and life expectancy. Lancet. 2012;380(9838):219-29.

11. Bull FC, Maslin TS, Armstrong T. Global Physical Activity Questionnaire (GPAQ): Nine Country Reliability and Validity Study. J Phys Act Health. 2009; 6(6):790-804.

12. Cleland CL, Hunter RF, Kee F, Cupples ME, Sallis JF, Tully MA. Validity of the Global Physical Activity Questionnaire (GPAQ) in assessing levels and change in moderate-vigorous physical activity and sedentary behaviour. BMC Public Health. 2014;14:1-11.

13. Mathews E, Salvo D, Sarma PS, Thankappan KR, Pratt M. Adapting and Validating the Global Physical Activity Questionnaire (GPAQ) for Trivandrum, India, 2013. Prev Chronic Dis. 2016:13:E53.

14. Craig CL, Marshall AL, Sjostrom M, Bauman AE, Booth ML, Ainsworth BE, Pratt M, Ekelund U, Yngve A, Sallis JF, et al. International physical activity questionnaire: 12-country reliability and validity. Med Sci Sports Exerc. 2003;35(8):1381-95.

15. Guidelines for data processing and analysis of the International Physical Activity Questionnaire (IPAQ)-short and long forms [https://docs.google. $\mathrm{com} /$ viewer?a=v\&pid=sites\&srcid=ZGVmYXVsdGRvbWFpbnx0aGVpcGFxfGd4 OjE0NDgxMDk3NDU1YWRIZTM] Accessed: 20 Jan 2017.

16. Hoos T, Espinoza N, Marshall S, Arredondo EM. Validity of the Global Physical Activity Questionnaire (GPAQ) in adult Latinas. J Phys Act Health. 2012;9(5):698-705

17. Laeremans M, Dons E, Avila-Palencia I, Carrasco-Turigas G, Orjuela JP, Anaya E, Brand C, Cole-Hunter T, de Nazelle A, Gotschi T, et al. Physical activity and sedentary behaviour in daily life: A comparative analysis of the Global Physical Activity Questionnaire (GPAQ) and the SenseWear armband. PLoS One. 2017:12(5):e0177765.

18. Sitthipornvorakul $E$, Janwantanakul $P$, van der Beek AJ. Correlation between pedometer and the Global Physical Activity Questionnaire on physical activity measurement in office workers. BMC Res Notes. 2014;7:280.

19. Metcalf KM, Baquero BI, Coronado Garcia ML, Francis SL, Janz KF, Laroche $\mathrm{HH}$, Sewell DK. Calibration of the global physical activity questionnaire to Accelerometry measured physical activity and sedentary behavior. BMC Public Health. 2018:18(1):412.

20. Wanner M, Hartmann C, Pestoni G, Martin BW, Siegrist M, Martin-Diener E. Validation of the Global Physical Activity Questionnaire for self-administration in a European context. BMJ Open Sport Exerc Med. 2017;3(1):e000206.

21. Rivière F, Widad FZ, Speyer E, Erpelding M-L, Escalon $H$, Vuillemin A Reliability and validity of the French version of the global physical activity questionnaire. J Sport Health Sci. 2018;7(3):339-45.

22. Chu AH, Ng SH, Koh D, Muller-Riemenschneider F. Reliability and Validity of the Self- and Interviewer-Administered Versions of the Global Physical Activity Questionnaire (GPAQ). PLoS One. 2015;10(9):e0136944.

23. Global Physical Activity Questionnaire (GPAQ) Analysis Guide V2 [https:// www.who.int/ncds/surveillance/steps/GPAQ\%20Instrument\%20and\%2 OAnalysis\%20Guide\%20v2.pdf] Accessed: 03 Feb 2018.

24. Herrmann SD, Heumann KJ, Der Ananian CA, Ainsworth BE. Validity and Reliability of the Global Physical Activity Questionnaire (GPAQ). Meas Phys Educ Exerc Sci. 2013:17(3):221-35.

25. The website for the International Physical Activity Questionnaire www.ipaq. ki.se [https://sites.google.com/site/theipaq/] Accessed: 20 Jan 2017.

26. Trost SG, Owen N, Bauman AE, Sallis JF, Brown W. Correlates of adults' participation in physical activity: review and update. Med Sci Sports Exerc. 2002;34(12):1996-2001

27. Freedson PS, Melanson E, Sirard J. Calibration of the Computer Science and Applications, Inc. accelerometer. Med Sci Sports Exerc. 1998;30(5):777-81. 
28. Ainsworth BE, Haskell WL, Herrmann SD, Meckes N, Bassett DR Jr, TudorLocke C, Greer JL, Vezina J, Whitt-Glover MC, Leon AS. 2011 Compendium of Physical Activities: a second update of codes and MET values. Med Sci Sports Exerc. 2011;43(8):1575-81.

29. Matthews CE, Ainsworth BE, Thompson RW, Bassett DR Jr. Sources of variance in daily physical activity levels as measured by an accelerometer. Med Sci Sports Exerc. 2002;34(8):1376-81.

30. Alkahtani SA. Convergent validity: agreement between accelerometry and the Global Physical Activity Questionnaire in college-age Saudi men. BMC Res Notes. 2016;9(1):436.

31. Mumu SJ, Ali L, Barnett A, Merom D. Validity of the global physical activity questionnaire (GPAQ) in Bangladesh. BMC Public Health. 2017;17(1):650.

32. Biswas A, Oh PI, Faulkner GE, Bajaj RR, Silver MA, Mitchell MS, Alter DA. Sedentary time and its association with risk for disease incidence, mortality, and hospitalization in adults: a systematic review and meta-analysis. Ann Intern Med. 2015;162(2):123-32.

33. Rosenberg DE, Bull FC, Marshall AL, Sallis JF, Bauman AE. Assessment of sedentary behavior with the International Physical Activity Questionnaire. J Phys Act Health. 2008:5(Suppl 1):S30-44.

34. Aa A, Schuh B, Sauvageot N, Zannad F, Olivier A, Guillaume M, Albert A, Larsson CA. Adherence to physical activity recommendations and its associated factors: an interregional population-based study. J Public Health Res. 2015;4(1):406.

35. Hamrik Z, Sigmundova D, Kalman M, Pavelka J, Sigmund E. Physical activity and sedentary behaviour in Czech adults: results from the GPAQ study. Eur J Sport Sci. 2014:14(2):193-8.

36. Shephard RJ. Limits to the measurement of habitual physical activity by questionnaires. Br J Sports Med. 2003;37(3):197-206.

\section{Publisher's Note}

Springer Nature remains neutral with regard to jurisdictional claims in published maps and institutional affiliations.

Ready to submit your research? Choose BMC and benefit from:

- fast, convenient online submission

- thorough peer review by experienced researchers in your field

- rapid publication on acceptance

- support for research data, including large and complex data types

- gold Open Access which fosters wider collaboration and increased citations

- maximum visibility for your research: over $100 \mathrm{M}$ website views per year

At $\mathrm{BMC}$, research is always in progress.

Learn more biomedcentral.com/submissions 